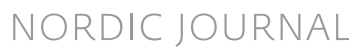 \\ of Science and Technology Studies
}

\section{ABOUT THE COVER ARTIST}

\author{
Elin Tanding Sørensen
}

Elin Tanding Sørensen is a landscape architect and visual artist. She is currently a PhD-fellow at the Faculty of Landscape and Society, Norwegian University of Life Sciences, and works as a freelancer with the enterprise Urban Living Laboratory. Her project is an art based doctoral study, where one aim is to fuse methods from the arts, landscape architecture, and science for the sake of arriving at visionary urban design propositions for the urban tidal zone. The project addresses the cultural and biological enrichment of urban hard surfaces through a transdisciplinary approach. The study initiates a series of living labs developed for selected sites along the Oslo Harbour Promenade, in order to achieve new understanding of the land-sea transitional area as a landscape for urban development through site-specific works. The aspiration is to shed light on the underlying forms of knowledge particular to the field of arts and landscape architecture. The study looks at eco-engineering from a landscape perspective - where landscape architecture can be a critical tool for re-envisioning 'new urban tidalscapes'. The methodological approach is hands-on - taking place as an exchange between long-term observations and 1:1 fieldwork including underwater studies with diverse, constructing landscapes by means of technical drawings (AutoCAD), clay models and sketches (by hand), and digital 3D models. The aim is to arrive at an increased understanding of how new urban tidalscapes may be designed and developed, and by this extend the city's 'green infrastructure' into the sea.

\begin{abstract}
Ålegras (Zostera marina), glassmaneter (Aurelia aurita) / Oslofjorden. Digital collage: Elin T. Sørensen (c) BONO 2018. Under water photo: Jonas Thormar. (Tr. Eelgrass, Jellyfish / The Oslofjord). Featured on the Cover of this issue is one example of Sørensen's visual work. Sørensen describes that Jellyfish are some of the world's oldest multicellular organisms that can communicate and have a sense of direction, despite not having a brain. She stresses the problematic dichotomy between humans and nature systems, and the Cover picture presents a suggestive integration of the two.
\end{abstract}

To learn more about Elin T. Sørensen and her work, visit her NMBU website: https://www.nmbu.no/prosjekter/node/35003 and the Community initiative Kongshavn Bad: https://www.facebook.com/ pg/Kongshavn-Bad-209657369813892/posts/?ref=page internal 